\title{
West Nile Virus Lineage 2 as a Cause of Zoonotic Neurological Disease in Humans and Horses in Southern Africa
}

\author{
Marietjie Venter ${ }^{1,2}$ and Robert Swanepoel ${ }^{3}$
}

\begin{abstract}
West Nile virus (WNV) is widely distributed in South Africa, but since a few cases of neurological disease have been reported from this region, endemic lineage 2 strains were postulated to be of low virulence. Several cases of nonfatal encephalitis in humans as well as fatal cases in a foal, dog, and ostrich chicks have, however, been associated with lineage $2 \mathrm{WNV}$ in South Africa. The pathogenesis of lineage $2 \mathrm{WNV}$ strains was investigated using mouse neuroinvasive experiments, gene expression experiments, and genome sequence comparisons which indicated that lineage 2 strains that are highly pathogenic exist. To determine whether cases of WNV were being missed in South Africa, horses with fever and neurological disease were investigated. Several cases of WNV were identified, all associated with severe neurological disease, $85 \%$ of which had to be euthanized or died. All cases positive by RT-PCR were shown to belong to lineage 2 WNV by DNA sequencing and phylogenetic analysis. Two cases of occupational infection were investigated, including a case of zoonotic transmission to a veterinarian who performed an autopsy on one of the horses as well as a laboratory infection after a needle stick injury with a neuroinvasive lineage 2 strain. Both resulted in neurological disease. Cytokine expression was investigated in the second case to assess the immunopathogenesis of WNV. Collectively, these studies suggest that lineage $2 \mathrm{WNV}$ may be significantly under estimated as a cause of neurological disease in South Africa.
\end{abstract}

Key Words: Cytokines—Lineage 2—Neurological disease—West Nile Virus—Zoonosis.

\section{Introduction}

D ESPITE beING WIDELy Distributed in Southern Africa, few West Nile virus (WNV) cases have been reported from this region, which lead to the hypothesis that strains in the region may be less virulent than those that caused the outbreaks in the Northern hemisphere (Lanciotti et al. 2002). To investigate the disease potential of Southern African WNV strains, phylogenetic comparisons (Burt et al. 2002), mouse neuroinvasive experiments (Beasley et al. 2002, Venter et al. 2005), gene expression experiments (Venter et al. 2005), genome sequencing (Botha et al. 2008), and human and horse cases (Venter et al. 2009a, 2009b, 2010) were investigated. This article reviews the findings of these studies.

\section{WNV Epidemiology and Clinical Presentation in Humans and Animals}

WNV, a mosquito-borne Flavivirus, is widely distributed in Africa, Asia, Europe, and Australia and has recently spread to the Western hemisphere, where its presence was recognized in the north-eastern United States in 1999 (Smithburn et al. 1940, Lanciotti et al. 1999). Although most infections are benign, $\sim 20 \%$ of human cases present with fever, a rash, arthralgia, and myalgia, whereas $\sim 1 \%$ of these may develop severe diseases, including meningoencephalitis, encephalitis, polio-like flaccid paralysis, and, in rare cases, hepatitis, myocarditis, pancreatitis (Petersen and Marfin 2002), and death (Hayes et al. 2005). Recent outbreaks of WNV infections in the United States, Eastern Europe, and Israel have been

\footnotetext{
${ }^{1}$ Respiratory and Zoonotic Disease Program, Department of Medical Virology, Faculty of Health Sciences, University of Pretoria, Pretoria, South Africa.

${ }^{2}$ Respiratory Virus Unit and ${ }^{3}$ Special Pathogens Unit, National Institute for Communicable Diseases, Sandringham, South Africa.
} 
characterized by relatively high rates of potentially fatal neurological complications, especially in elderly human patients, birds, and horses (Cantile et al. 2001, Murgue et al. 2001, Durand et al. 2002, Steinman et al. 2002).

Serological studies suggest that asymptomatic infections frequently occur in horses (Guthrie et al. 2003, Nielsen et al. 2008), but neurological infections result in a high case fatality rate $(30 \%-40 \%)$ (Ward et al. 2006). Signs in severely affected horses include ataxia, weakness, recumbency, and muscle fasciculation (Ostlund et al. 2001, Dauphin et al. 2004, Durand et al. 2004, Schuler et al. 2004, Ward et al. 2004). In 2002, the largest outbreak of WNV encephalomyelitis in horses was recorded in the United States, which involved 15,257 cases in over 40 states (Dauphin et al. 2004). In the following year, there was an outbreak of 9832 cases in humans across the United States, the largest ever recorded in the Northern hemisphere (Hayes et al. 2005). The number of cases of horses in the United States was significantly reduced after the introduction of an inactivated animal vaccine and as the virus became endemic (Schuler et al. 2004, Beasley 2005, Dauphin and Zientara 2007).

\section{WNV Lineages}

Isolates of WNV fall into two major as well as a few minor genetic lineages. Lineage 1 is found in North America, North Africa, Europe, and Australia, whereas lineage 2 is endemic to Southern Africa and Madagascar (Lanciotti et al. 1999, Burt et al. 2002). Recently, additional lineages have been reported in Central and Eastern Europe (lineages 3 and 4) (Lvov et al. 2004, Bakonyi et al. 2005) and India (lineage 5) (Bondre et al. 2007). Although initial speculation suggested that lineage 1 strains were more pathogenic than lineage 2 strains, phylogenetic analysis and mouse neuroinvasive experiments have shown that highly neuroinvasive and mild strains exist in both lineages and that the neuroninvasive phenotype is related to genotype and not to lineage (Beasley et al. 2001). It was suggested that the perceived virulence of WNV in recent epidemics probably reflects high medical alertness, active surveillance programs, and the emergence and re-emergence of existing strains of WNV in geographic locations with immunologically naive populations (Burt et al. 2002). The lineage 1 strain that was imported into North America in 1999/ 2000 was shown to be highly neuroinvasive in mice, and its uniform spread across the continent may also have accounted for the high incidence of neuroinvasive infections (van der Poel 1999, Beasley et al. 2001, Burt et al. 2002).

\section{Lineage 2 Pathogenesis}

The perceived increase in severity of infections in the Northern hemisphere raised the question of whether WNV strains with increased pathogenicity had emerged or whether the virulence of the virus had been previously underestimated (Burt et al. 2002). The hypothesis that lineage 1 is associated with severe disease and lineage 2 only with mild disease was made after phylogenetic analysis which demonstrated that strains associated with severe disease in North Africa, Europe, Asia, and North America all belonged to lineage 1, whereas lineage 2 consists solely of isolates from Southern Africa and Madagascar wherein few cases of neurological disease have been reported (Lanciotti et al. 1999). However, comparison of the phylogenetic relationships and neuroinvasiveness in mice of South African and North American WNV isolates indicated that pathogenicity is genotype specific and not related to lineage, source of isolate, geographic distribution, passage level, or year of isolation, as all strains that were associated with severe disease in Southern Africa clustered with lineage 2 (Beasley et al. 2002, Burt et al. 2002).

Recently, a lineage 2 strain was isolated from encephalitic birds in central Europe, suggesting that lineage 2 strains have the ability to spread outside of their known geographic range and may cause severe disease in birds outside of endemic countries.

The lineage 2 strain caused encephalitis and death in a sparrow hawk (Accipiter nisus) and several goshawk (Accipiter gentilis) fledglings in southeast of Hungary during the summers of 2004 and 2005 and appears to have established itself in the region (Bakonyi et al. 2006, Erdelyi et al. 2007).

\section{WNV in Southern Africa}

Historically, WNV was reported to be widely endemic in South Africa, and human infections tended to be sporadic, with large epidemics occurring only when unusually high rainfall or hot weather favors breeding of the mosquito vectors (McIntosh 1980). The WNV caused one of the largest outbreaks ever recorded in humans in the Karoo in 1974, involving tens of thousands of people. During this outbreak, thousands of people visited their local clinicians, although no cases of neurological disease were reported. High attack rates were observed in humans with the worst-affected towns in the Karoo having $50 \%-80 \%$ seroconversion, likely due to the high prevalence of Culex Univittatus, which was the main vector (McIntosh et al. 1976). This mosquito is also likely responsible for sporadic cases in interepidemic periods. Seroprevalence investigations in the 1950s-1970s in South Africa indicated that $17 \%$ of people in the Karoo, $8 \%$ in the Highveld, and 2\% in Natal had antibodies for WNV outside of epidemics (McIntosh et al. 1976). No recent serological data are available. An epizootic involving WNV and Sindbis virus was also reported in the 1980s in the Witwatersrand area of the Gauteng Province in South Africa, and this affected hundreds of people (Jupp 2001).

Since then, the number of confirmed human cases per annum ranged from 5 to 15 . It is, however, suspected that only a proportion of cases are subjected to laboratory investigation. Despite the low number of reported cases, severe disease has been recognized in Southern Africa, including fatal hepatitis; several nonfatal encephalitis cases in humans; and deaths in an ostrich chick, a foal, and a dog (Burt et al. 2002, Botha et al. 2008).

\section{WNV in Horses in South Africa}

A serologic survey carried out in thoroughbred horses in 2003 confirmed that WNV is widely distributed throughout South Africa with $11 \%$ of yearlings and up to $75 \%$ of their dams being exposed (Guthrie et al. 2003). After the study, it was postulated that endemic lineage $2 \mathrm{WNV}$ strains do not cause neuroinvasive disease in horses, because all these horses were healthy with no record of disease. In addition, 2 sero-negative horses were inoculated with a recent $\mathrm{WNV}$ lineage 2 strain (SPU381/00) from a person with benign disease and did not develop clinical signs. However, subsequent studies have shown that SPU381/00 is a mild strain of low 
neuroinvasiveness in mice compared with certain other South African strains (Venter et al. 2005). Today, it is also clear that subclinical cases are frequently reported in horses in the United States (Nielsen et al. 2008). In addition, experimental infection of 12 horses with the highly neuroinvasive NY99 strain resulted in neuroinvasive disease in only one animal, with the rest failing to develop clinical signs despite seroconverting (Bunning et al. 2002, Nielsen et al. 2008).

This raised the question whether neurological disease may be missed in horses in South Africa. To address this, 79 serum or brain specimens from horses that presented with unexplained fever (48) and/or neurological symptoms (31) were screened over a period of 18 months for WNV by RT-PCR and WNV IgM ELISA, and this was followed by plaque reduction neutralization tests (Venter et al. 2009b). WNV infection was identified in 6 out of 31 neurological cases $(19 \%)$, of which 5 cases were fatal or had to be euthanized. Clinical signs included ataxia, weak hinds and/or forelimbs, and paresis; complete paralysis; seizures and chewing; partial blindness; jaundice and/or hepatitis; and myosis of the pupils. Recumbency, muscle twitching, chewing fits, and seizures were observed in certain fatal cases. Coinfection with African horse sickness virus (AHSV) was detected in two cases and probably increased the severity of disease. Cases came from the Gauteng- and North West and the Western Cape Provinces of South Africa (Venter et al. 2009b) as well as Tanzania (Unpublished data). All three RT-PCR-positive cases were shown to belong to lineage 2 by DNA sequencing (Venter et al. 2009b), and this held good even with regard to the case from Tanzania (unpublished data).

The WNV positive horses were also tested for AHSV, equine encephalosis virus, and equine herpes virus plus rabies in severe fatal cases. The AHSV was detected in two horses with fatal disease; however, four were only positive for WNV, whereas none of the other viruses were detected. Three RTPCR positive cases were sequenced and shown to belong to lineage 2 on the basis of the nonstructural 5 (NS5) gene. The $E$, $C$, and NS5 genes of virus isolated from the brain of one fatal case were sequenced and shown to be closely related to a lineage 2 strain isolated from humans with encephalitic disease in South Africa. These findings confirm that WNV lineage 2 causes fatal neurological disease in horses in South Africa, and cases may have been previously missed. Human and horse cases may be underdetected, and horses may be useful sentinels to detect virus activity in the absence of bird deaths in South Africa (Venter et al. 2009b).

\section{Comparison of Mouse Gene Expression Following Neuroinvasive Strains in Both Lineages}

To identify candidate host genes associated with WNV pathogenesis, DNA microarray technology was used to measure gene expression levels in brain, liver, and spleen tissues of mice infected with WNV lineage 1 and 2 strains (Venter et al. 2005). The six strains selected in this study had caused either severe or benign infection in humans and birds, whereas the seventh strain was a mosquito isolate. All strains were characterized as highly or less neuroinvasiveness in mice, and highly neuroinvasive strains were identified in lineage 1 and 2 . The WNV lineage 2 strains that had similar neuroinvasive levels in mice to lineage 1 strains which caused neurological disease in the United States were identified.
Similar genes were induced by highly neuroinvasive lineage 1 and 2 strains, and increased expression of 47 genes in the brain, 111 genes in the liver, and 70 genes in the spleen, relative to the 3 least neuroinvasive strains, were identified. Genes involved in interferon signaling pathways, protein degradation, $\mathrm{T}$ cell recruitment, major histocompatibility complex class I and II antigen presentation, and apoptosis were identified. These genes may have both pathogenic and protective effects, but increased expression of certain acute proteins, central nervous system-specific proteins, and proteins associated with $\mathrm{T}$ cell hepatitis implicate mechanisms related to exalted virulence (Venter et al. 2005).

\section{Genetic Determinants of the Virulence of Lineage 2 Strains}

The complete genomes were sequenced for four lineage 2 WNV strains isolated from patients in South Africa who had mild or severe WNV infections. These strains had been previously shown to be highly or less neuroinvasive in mice and induced genes similar to corresponding highly or less neuroinvasive lineage 1 strains in mice in the study described in the previous paragraph. Phylogenetic and amino acid comparison of highly and less neuroinvasive lineage 2 strains identified most variability in the NS genes, especially the NS protein 5 gene. All South African lineage 2 strains possessed the envelope-protein glycosylation site previously postulated to be associated with virulence (Beasley et al. 2005), although the prototype lineage 2 strain from Uganda (B956D117B3) and the nonneuroinvasive Madagascar strain AnMg798 contained deletions in the glycosylation site of the E-protein relative to the South African strains, which will prevent glycosylation. Major deletions also existed in the $3^{\prime}$ noncoding region of two of the lineage 2 strains that were previously shown to be either less or not neuroinvasive relative to the highly neuroinvasive strains sequenced in this study (Botha et al. 2008).

Although phenotypic investigations of mutations identified in lineage 2 strains are lacking, several studies have been described for lineage 1 strains. Lineage 1 viruses having phenotypes of reduced virulence in mice and inefficient growth in culture were identified in Mexico. Molecular characterization of these isolates suggested that mutations leading to loss of E-protein glycosylation together with mutations in the NS protein genes may be associated with attenuation (Beasley et al. 2005). In another study, comparisons between the prototype strain (B956) and a variant obtained by molecular mutation (B956D117B3) revealed changes in the $E$ and NS genes, which resulted in reduced virulence for mice (Yamshchikov et al. 2004). None of the attenuated isolates could, however, be correlated with clinical disease in humans, because they were either isolated from birds or modified in culture. Substitution of the cysteine by serine at position 102 of the NS4B by site-directed mutagenesis leads to the formation of a $41^{\circ} \mathrm{C}$ temperature sensitive phenotype as well as attenuation of the neuroinvasive and neurovirulent phenotypes in mice (Wicker et al. 2006). An adaptive mutation of Glu to Gly at residue 249 (E249G) in the NS4B gene resulted in reduced RNA synthesis in host cells (Puig-Basagoiti et al. 2007). An infectious clone of the NY99 strain, which is highly virulent in American crows, was compared in vitro with a Kenya strain (KEN-3829) that has reduced virulence in American crows. The KEN-3829 strain showed a 6500-fold reduction in viral 
RNA production compared with a 17 -fold reduction in the NY99 strain at temperatures $>44^{\circ} \mathrm{C}$, suggesting that efficient replication at high temperatures, as experienced in birds, could be an important virulence factor of the NY99 strain (Kinney et al. 2006).

\section{Risk of Zoonotic and Laboratory Infections}

Two occupational zoonotic human WNV cases were identified in South Africa, where patients were infected with WNV lineage 2 strains, one laboratory infection by needle stick injury and one in a veterinary student during exposure to infected horse brain while performing an autopsy. The two cases were used to investigate the pathogenic potential of lineage 2 strains in otherwise healthy adults.

A foal that had to be euthanized with neurological disease was autopsied at the Onderstepoort Faculty of Veterinary Science, University of Pretoria. The signs included fever, Schiff-Sherrington signs (exaggerated stretch reflexes following spinal cord lesions), as well as a white blood cell count of $32 \times 10^{9} / \mathrm{L}$ (normal range in horses $5.5-12 \times 10^{9} / \mathrm{L}$ ). Although it initially responded to treatment, the foal had a relapse with neurological deterioration and rectal prolapse and was euthanized. The autopsy was performed by a veterinary pathologist and two students. The brain and spinal cord were removed for histopathology, and a sample was taken for bacteriological and virological investigations. The WNV was identified by RT-PCR in the brain. Five days after the autopsy, the veterinary student who removed the brain developed fever, malaise, myalgia, neck stiffness, and severe headache. A rash appeared 2 days later. Symptoms persisted for $\sim 10$ days. The patient was treated symptomatically and with bed rest. The WNV was isolated in mice from his serum and confirmed by PCR. Sequencing and phylogenetic analysis of part of the NS5 gene of WNV obtained from the foal's brain, the mouse isolate as well as the student's serum was identical and confirmed to be lineage 2 in all cases. Although the viremia in humans and horses is generally too low to support infection of mosquitoes, the viral load may be high in nerve tissues of fatal cases that test positive by RT-PCR or immunohistochemistry despite serum being negative (reviewed in Jupp 2001, Hayes and Gubler 2006). The invasive nature of autopsy may pose a higher risk for infection by mucous membrane. Gloves were the only protective gear worn during the autopsy; however, following this incident, biosafety measures have been improved to include gloves, masks, and eye visor at the facility (Venter et al. 2010).

In the second case, laboratory-acquired WNV meningoencephalitis occurred in a 29-year-old immunocompetent female scientist at the NICD after a needle stick injury with neuroinviasive lineage 2 WNV strain, SPU93/01, as described in Venter et al. (2009a). This strain was previously isolated from a patient with nonfatal encephalitis (Burt et al. 2002, Botha et al. 2008). As part of this investigation, blood was taken on the day of infection and from the day symptoms started to provide a rare opportunity to investigate cytokine expression from infection to recovery. The patient developed backache, neck stiffness, and malaise on day 7 postinfection; rash, mild fever, and meningoencephalitis symptoms, including severe headache and photophobia on day 8; and on day 9, arthralgia as well as a tender spleen and liver was reported. Symptoms continued for 19 days and were biphasic.
Although the patient recovered by day 26, photosensitivity persisted for several months. Due to the nature of her work, the scientist had received Aventis Pasteur yellow fever virus vaccine 6 months before the accident and had satisfactory seroconversion yet was not protected from neurological disease. This contradicts the notion that yellow fever vaccine may protect patients from WNV disease (Tesh et al. 2002, Yamshchikov et al. 2005). The immunopathogenesis of WNV was investigated by measuring 16 cytokines with pathogenic and protective potential in the patient's serum collected on days $0,8,9,10,11,13,16$, and 26 postinfection. The most significant changes relative to a healthy control were noted for IFN $\alpha$ on days 8,9 , and 13 postinfection; IP10 on day 8; and IL13, which was increased from day 0 to 11 . Proinflammatory cytokines IL6 and IL8 increased moderately on day 16 and IL-15 on day 11. TNF $\alpha$ and IL5 increased slightly on day 11, whereas no significant change was noted for EOTAXIN, IFN $\gamma$, MIP1 $\alpha$, MIP1 $\beta$, RANTES, IL4, IL9, or IL10. The authors suggested that the identified cytokines may serve as additional targets for therapeutic interventions either by suppressing the proinflammatory response (IL13, IL6, and IL8) or supplementing Th1 type responses (TNF $\alpha$ and IFN $\gamma$ ) (Venter et al. 2009a). Improvement in mentation, speech, and eventual recovery was previously reported after experimental treatment of 2 WNV patients with encephalitis and with synthetic IFN $\alpha 2 b$ (Kalil et al. 2005). Data from this laboratory infection suggest that IFN $\alpha$ was also increased in this patient who survived a neurological WNV infection and could therefore be of benefit. Both of these cases demonstrated the potential of lineage $2 \mathrm{WNV}$ strains to cause neurological disease in otherwise healthy individuals.

\section{Conclusion}

It has been demonstrated that lineage $2 \mathrm{WNV}$ strains exist that are highly neuroinvasive and cause neurological infections of humans and animals in South Africa. Cases in horses may have been missed in the past, because WNV transmission occurs at the same time as annual outbreaks of AHSV. Increased awareness among veterinarians and medical clinicians of the potential for WNV to cause severe disease may lead to an increase in the number of cases detected annually. Human cases of aseptic meningoencephalitis should be screened to determine whether WNV cases can be detected.

WNV may be under appreciated as a cause of neurological disease in humans and horses in Southern Africa and should be considered in humans and animals that develop acute meningoencephalitis.

\section{Acknowledgments}

This review summarizes the findings of several papers since 2002. The authors thank the students and veterinary pathologists at the University of Pretoria; scientists at the Special Pathogens Unit, NICD; and veterinarians at the Onderstepoort Veterinary Institute and in private practice across South Africa who contributed to different aspects of the work. The authors thank the National Research Foundation, The Poliomyelitis Research foundation, and the National Health Laboratory Services for funding. This work has been cleared by the human ethics committee of the University of Pretoria and the animal ethics committee of the National Health Laboratory Services. 


\section{Disclosure Statement}

The authors declare no conflict of interest.

\section{References}

Bakonyi, T, Hubalek, Z, Rudolf, I, Nowotny, N. Novel flavivirus or new lineage of West Nile virus, central Europe. Emerg Infect Dis 2005; 11:225-231.

Bakonyi, T, Ivanics, E, Erdelyi, K, Ursu, K, et al. Lineage 1 and 2 strains of encephalitic West Nile virus, central Europe. Emerg Infect Dis 2006; 12:618-623.

Beasley, DW. Recent advances in the molecular biology of West Nile virus. Curr Mol Med 2005; 5:835-850.

Beasley, DW, Li, L, Suderman, MT, Barrett, AD. Mouse neuroinvasive phenotype of West Nile virus strains varies depending upon virus genotype. Virology 2002; 296:17-23.

Beasley, DW, Li, L, Suderman, MT, Barrett, AD. West Nile virus strains differ in mouse neurovirulence and binding to mouse or human brain membrane receptor preparations. Ann N Y Acad Sci 2001; 951:332-335.

Beasley, DW, Whiteman, MC, Zhang, S, Huang, CY, et al. Envelope protein glycosylation status influences mouse neuroinvasion phenotype of genetic lineage 1 West Nile virus strains. J Virol 2005; 79:8339-8347.

Bondre, VP, Jadi, RS, Mishra, AC, Yergolkar, PN, et al. West Nile virus isolates from India: evidence for a distinct genetic lineage. J Gen Virol 2007; 88(Pt 3):875-884.

Botha, EM, Markotter, W, Wolfaardt, M, Paweska, JT, et al. Genetic determinants of virulence in pathogenic lineage 2 West Nile virus strains. Emerg Infect Dis 2008; 14:222-230.

Bunning, ML, Bowen, RA, Cropp, CB, Sullivan, KG, et al. Experimental infection of horses with West Nile virus. Emerg Infect Dis 2002; 8:380-386.

Burt, FJ, Grobbelaar, AA, Leman, PA, Anthony, FS, et al. Phylogenetic relationships of southern African West Nile virus isolates. Emerg Infect Dis 2002; 8:820-826.

Cantile, C, Del Piero, F, Di Guardo, G, Arispici, M. Pathologic and immunohistochemical findings in naturally occurring West Nile virus infection in horses. Vet Pathol 2001; 38:414421.

Dauphin, G, Zientara, S. West Nile virus: recent trends in diagnosis and vaccine development. Vaccine 2007; 25:55635576.

Dauphin, G, Zientara, S, Zeller, H, Murgue, B. West Nile: worldwide current situation in animals and humans. Comp Immunol Microbiol Infect Dis 2004; 27:343-355.

Durand, B, Chevalier, V, Pouillot, R, Labie, J, et al. West Nile virus outbreak in horses, southern France, 2000: results of a serosurvey. Emerg Infect Dis 2002; 8:777-782.

Durand, JP, Simon, F, Tolou, H. [West Nile virus: in France again, in humans and horses]. Rev Prat 2004; 54:703-710.

Erdelyi, K, Ursu, K, Ferenczi, E, Szeredi, L, et al. Clinical and pathologic features of lineage 2 West Nile virus infections in birds of prey in Hungary. Vector Borne Zoonot Dis 2007; 7:181-188.

Guthrie, AJ, Howell, PG, Gardner, IA, Swanepoel, RE, et al. West Nile virus infection of Thoroughbred horses in South Africa (2000-2001). Equine Vet J 2003; 35:601-605.

Hayes, EB, Gubler, DJ. West Nile virus: epidemiology and clinical features of an emerging epidemic in the United States. Annu Rev Med 2006; 57:181-194.

Hayes, EB, Sejvar, JJ, Zaki, SR, Lanciotti, RS, et al. Virology, pathology, and clinical manifestations of West Nile virus disease. Emerg Infect Dis 2005; 11:1174-1179.
Jupp, PG. The ecology of West Nile virus in South Africa and the occurrence of outbreaks in humans. Ann N Y Acad Sci 2001; 951:143-152.

Kalil, AC, Devetten, MP, Singh, S, Lesiak, B, et al. Use of interferonalpha in patients with West Nile encephalitis: report of 2 cases. Clin Infect Dis 2005; 40:764-766.

Kinney, R, Huang, C-H, Whiteman, M, Bowen, R, et al. Avain virulence and thermostable replication of the North American strain of West Nile virus. J Gen Virol 2006; 87:3611-3622.

Lanciotti, RS, Ebel, GD, Deubel, V, Kerst, AJ, et al. Complete genome sequences and phylogenetic analysis of West Nile virus strains isolated from the United States, Europe, and the Middle East. Virology 2002; 298:96-105.

Lanciotti, RS, Roehrig, JT, Deubel, V, Smith, J, et al. Origin of the West Nile virus responsible for an outbreak of encephalitis in the northeastern United States. Science 1999; 286:2333-2337.

Lvov, DK, Butenko, AM, Gromashevsky, VL, Kovtunov, AI, et al. West Nile virus and other zoonotic viruses in Russia: examples of emerging-reemerging situations. Arch Virol Suppl 2004; (18):85-96.

McIntosh, B (1980). The epidemiology of arthropod-borne viruses in southern Africa. University of Pretoria, Pretoria, South Africa.

McIntosh, B, Jupp, P, Dos Santos, I, Meenehan, G. Epidemics of West Nile and Sindbis viruses in South Africa and Culex (Culex) univittatus. S Afr J Sci 1976; 72:295-300.

Murgue, B, Murri, S, Zientara, S, Durand, B, et al. West Nile outbreak in horses in southern France, 2000: the return after 35 years. Emerg Infect Dis 2001; 7:692-696.

Nielsen, CF, Reisen, WK, Armijos, MV, Maclachlan, NJ, et al. High subclinical West Nile virus incidence among nonvaccinated horses in northern California associated with low vector abundance and infection. Am J Trop Med Hyg 2008; 78:45-52.

Ostlund, EN, Crom, RL, Pedersen, DD, Johnson, DJ, et al. Equine West Nile Encephalitis, United States. Emerg Infect Dis 2001; 7:665-660.

Petersen, LR, Marfin, AA. West Nile virus: a primer for the clinician. Ann Intern Med 2002; 137:173-179.

Puig-Basagoiti, F, Tilgner, M, Bennett, C, Yangsheng, Z, et al. A mouse cell-adapted NS4B mutation attenuates West Nile virus RNA synthesis. Virology 2007; 361:229-241.

Schuler, LA, Khaitsa, ML, Dyer, NW, Stoltenow, CL. Evaluation of an outbreak of West Nile virus infection in horses: 569 cases (2002). J Am Vet Med Assoc 2004; 225:1084-1089.

Smithburn, K, Huges, T, Burke, A, Paul, J. A neurotropic virus isolated from the blood of a native Uganda. Am J Trop Med Hyg 1940; 20:471-492.

Steinman, A, Banet, C, Sutton, GA, Yadin, H, et al. Clinical signs of West Nile virus encephalomyelitis in horses during the outbreak in Israel in 2000. Vet Rec 2002; 151:47-49.

Tesh, RB, Travassos da Rosa, AP, Guzman, H, Araujo, TP, et al. Immunization with heterologous flaviviruses protective against fatal West Nile encephalitis. Emerg Infect Dis 2002; 8:245-251.

van der Poel, WH. [West Nile-like virus is the cause of encephalitis in humans and horses and the death of hundreds of birds in New York]. Tijdschr Diergeneeskd 1999; 124: 704-705.

Venter, M, Burt, FJ, Blumberg, L, Fickl, H, et al. Cytokine induction after laboratory-acquired West Nile virus infection. N Engl J Med 2009a; 360:1260-1262.

Venter, M, Human, S, Zaayman, D, Gerdes, GH, et al. Lineage 2 West Nile virus as cause of fatal neurologic disease in horses, South Africa. Emerg Infect Dis 2009b; 15:877-884. 
Venter, M, Myers, TG, Wilson, MA, Kindt, TJ, et al. Gene expression in mice infected with West Nile virus strains of different neurovirulence. Virology 2005; 342:119-140.

Venter, M, Steyl, J, Human, S, Weyer, J, et al. Transmission of West Nile virus during horse autopsy. Emerg Infect Dis 2010; 16:573-575.

Ward, MP, Levy, M, Thacker, HL, Ash, M, et al. Investigation of an outbreak of encephalomyelitis caused by West Nile virus in 136 horses. J Am Vet Med Assoc 2004; 225:84-89.

Ward, MP, Schuermann, JA, Highfield, LD, Murray, K. Characteristics of an outbreak 255 of West Nile virus encephalomyelitis in a previously uninfected population of horses. Vet Microbiol 2006; 118:225-229.

Wicker, JA, Whiteman, MC, Beasley, DW, Davis, CT, et al. A single amino acid substitution in the central portion of the West Nile virus NS4B protein confers a highly attenuated phenotype in mice. Virology 2006; 349:245-253.

Yamshchikov, G, Borisevich, V, Kwok, CW, Nistler, R, et al. The suitability of yellow fever and Japanese encephalitis vaccines for immunization against West Nile virus. Vaccine 2005; 23:4785-4792.

Yamshchikov, G, Borisevich, V, Seregin, A, Chaporgina, E, et al. An attenuated West Nile prototype virus is highly immunogenic and protects against the deadly NY99 strain: a candidate for live WN vaccine development. Virology 2004; 330:304-312

Address correspondence to: Marietjie Venter Respiratory and Zoonotic Disease Program Department Medical Virology Faculty of Health Sciences University of Pretoria Pretoria South Africa

E-mail: marietjiev@nicd.ac.za 